\title{
Need for Bioequivalence Standards that Reflect the Clinical Importance of the Complex Pharmacokinetics of Paliperidone Palmitate Long-Acting Injectable Suspension
}

\author{
Ric M. Procyshyn ${ }^{1}$, Joel W. Lamoure ${ }^{2}$, Martin A. Katzman ${ }^{3}$, Pamela L. Skinner ${ }^{4}$, Stephen E. Sherman ${ }^{4}$ \\ ${ }^{1}$ British Columbia Mental Health \& Substance Use Services, Vancouver, BC, Department of Psychiatry, University of British \\ Columbia, Vancouver, BC. ${ }^{2}$ Telepharmacy Division, The Northwest Company, Winnipeg, MB. ${ }^{3}$ S.T.A.R.T. (Stress, Trauma, \\ Anxiety, Rehabilitation and Treatment) Clinic for the Mood and Anxiety Disorders, Toronto, ON, Department of Psychology, \\ Adler Graduate Professional School, Toronto, ON, Clinical Sciences, Northern Ontario School of Medicine, Laurentian and \\ Lakehead University, Sudbury and Thunder Bay, ON, Department of Psychology, Lakehead University, Thunder Bay, ON. \\ ${ }^{4}$ Janssen Inc. Toronto, ON.
}

Received, July 30, 2019; Revised, October 11, 2019; Accepted, October 30, 2019; Published, Nov 21, 2019.

\begin{abstract}
Paliperidone palmitate is a second generation antipsychotic, approved for the treatment of schizophrenia in the form of the long-acting injectable (LAI) products INVEGA SUSTENNA ${ }^{\circledR}$ (once monthly injection) and INVEGA TRINZA ${ }^{\circledR}$ (once every 3 months injection). Paliperidone palmitate dissolves slowly after deep intramuscular injection before being hydrolyzed to paliperidone and absorbed into the systemic circulation. The pharmacokinetic (PK) profile of the INVEGA SUSTENNA ${ }^{\circledR}$ formulation is biphasic, comprised of an initial relatively fast zero-order input, which allows rapid attainment of therapeutic concentrations without oral supplementation; and a subsequent maintained second-stage, first-order input, allowing for once monthly administration. Changes to the manufacturing processes can substantially alter the release characteristics of paliperidone palmitate LAI and consequently its PK profile. As an example, larger or smaller particle sizes of paliperidone palmitate can result in a delayed or accelerated release of paliperidone into the systemic circulation, respectively. Such changes are clinically relevant, as transient excursions above therapeutic plasma concentrations can be associated with an increased risk of adverse effects, including tachycardia, hypotension, QT prolongation, and extrapyramidal symptoms. Conversely, a delay in attaining therapeutic plasma concentrations of paliperidone on initiation of treatment, or a return to low plasma concentrations before the end of a dosing interval during repeated dosing, increases the risk of relapse. Given the integral relationship of the PK profile to the product's clinical effects, it is important to have bioequivalence standards that reflect the complexity of the paliperidone palmitate LAI PK profile if one is to consider therapeutic equivalence based on simple bioequivalence testing. Although both the EMA and U.S. FDA have product-specific guidelines to determine bioequivalence, their requirements differ substantially. In Canada, no LAI product-specific bioequivalence guidance exists for multiphasic medication delivery systems, and the recently revised Comparative Bioavailability Standards: Formulations Used for Systemic Effects guidance applies only to oral and non-injectable formulations. We recommend that new Canadian standards be developed for multiphasic and biphasic intramuscular / subcutaneous (IM/SC) products, including paliperidone palmitate LAI products, because, similar to modified-release oral dosage forms, a different PK profile in modified-release IM/SC products can result in clinically meaningful differences in safety, efficacy, and tolerability. To ensure bioequivalence for both newly initiated and switch patients, this paper proposes bioequivalence standards that could be adopted in Canada that include two studies, a multipledose cross-over study, and a single-dose study with partial AUC metrics.
\end{abstract}

\section{INTRODUCTION}

Schizophrenia is a chronic, severe, and disabling illness affecting about $0.6 \%$ of the population (1). The illness manifests earlier in men (in the late teens or early twenties) than in women (who are affected in the twenties to early thirties); however, it affects men and women with equal frequency.
Schizophrenia is usually diagnosed in people aged 17-35 years and requires long term treatment.

Poor adherence with antipsychotic treatment increases with the type and duration of treatment;

Corresponding Author: Pamela Skinner, Janssen Inc. 19 Green Belt Drive, Toronto, ON, Canada, Email: PSkinne2@its.jnj.com 
with patients becoming partially adherent or nonadherent over time (2). Discontinuation of medication is among the strongest risk factors for relapse, and thus adherence to treatment is important for positive treatment outcomes and remission (3). It has been reported that the risk of relapse is almost five-fold with the discontinuation of antipsychotic treatment within five years after initial recovery from the first episode of schizophrenia (4). Furthermore, non-adherence, or partial adherence, can also have a negative impact on patient outcomes, resulting in progressive relapse (5). In turn, relapse is associated with an exacerbation of positive and negative symptoms as well as deterioration of functioning, an increase use of mental health resources, possible involuntary commitment, and medication resistance $(6,7,8)$. The challenge of non-adherence in patients with schizophrenia has, in part, led to the development of long-acting injectable (LAI) antipsychotics, including paliperidone palmitate, which are designed to deliver medication over an extended period.

Currently there are two LAI suspensions of paliperidone palmitate available in Canada, designed to be administered intramuscularly (IM) either monthly (i.e. INVEGA SUSTENNA ${ }^{\circledR}$ ) or once every three months (i.e. INVEGA TRINZA ${ }^{\circledR}$ ) in patients already established on INVEGA SUSTENNA ${ }^{\circledR}$ $(9,10)$. The current paper will focus on the paliperidone palmitate once monthly (PP1M) formulation, although similar concepts might also be applied to other LAI products. PP1M has a unique sustained-release formulation, that allows for a oncemonthly (every 4 weeks) dosing interval. The recommended initiation regimen for $\mathrm{PP} 1 \mathrm{M}$, is 150 $\mathrm{mg}$ on treatment day 1 and $100 \mathrm{mg}$ on day 8 , both administered in the deltoid muscle. This regimen allows therapeutic concentrations to be reached rapidly without oral supplementation. The recommended subsequent monthly maintenance dose is $75 \mathrm{mg}$; with a recommended dose range of 25 $\mathrm{mg}$ to $150 \mathrm{mg}$ based on individual patient tolerability and/or efficacy.

Due to its extremely low water solubility, paliperidone palmitate dissolves slowly from where it is localized at the IM injection site. Once dissolved, paliperidone palmitate is hydrolyzed by esterases and the free paliperidone is absorbed into the systemic circulation. The absorption is ratelimited by its dissolution in the fluids at the injection site (11).
The increase in paliperidone plasma concentrations over the first few days following administration is temporally related to the onset of efficacy, with continued improvement in symptoms over the following 2 to 3 weeks (12). The resulting relationship between the Canadian Reference Product PP1M formulation and therapeutic efficacy underlines the need to ensure that new formulations ("test" products) of paliperidone palmitate LAI products be therapeutically equivalent to the reference product, regardless of whether the new product is a subsequent-entry product ("generic product") or a first-entry ("branded product") undergoing a formulation change or a line extension.

The United States (U.S.) Food and Drug Administration (FDA) considers "approved drug products to be therapeutic equivalents only if they are pharmaceutical equivalents for which bioequivalence has been demonstrated, and they can be expected to have the same clinical effect and safety profile when administered to patients under the conditions specified in the labeling" (13). A different approach is being taken in Canada where pharmaceutical equivalence has recently been redefined as "a new drug that, in comparison with another drug, contains identical amounts of the identical therapeutically active components, in comparable dosage forms, but that does not necessarily contain the same non-medicinal ingredients" (14). This newly introduced expansion of the definition of pharmaceutical equivalent that focuses on the therapeutically active components now allows for the inclusion of products with: 1) different hydrated or solvated forms, 2) different polymorphic forms, and 3) different salt forms (14). However, the related draft guidance currently excludes products where the differences in the medicinal ingredients include: 1) different esters, 2) different complexes, 3) difference clathrates, and 4) different isomers or mixtures with different proportions of isomers (15). Other regulatory agencies categorize different salts or esters of the medicinal ingredient as pharmaceutical alternatives, as they are regarded as different active ingredients, and therefore not considered therapeutically equivalent. On the contrary, the revisions to the definition of pharmaceutical equivalent in Canada have expanded the term to include some of these forms, allowing for their consideration for therapeutic equivalence $(13,14)$.

Health Canada also recently revised the Canadian regulatory standards required to 
demonstrate bioequivalence for formulations used for systemic effects; however, the revised guidance specifically excludes injectable IM and subcutaneous (SC) products (16). As such, Health Canada has not published regulatory pharmacokinetic (PK) measures of bioequivalence for multiphasic injectable formulations such as PP1M, whereas other jurisdictions have issued product-specific bioequivalence requirements for PP1M $(17,18)$. Despite some similarities in productspecific bioequivalence guidelines between the European Medicines Agency (EMA) and U.S. FDA, they do not align on all requirements. The greatest difference is that the U.S. FDA requires only one multiple-dose comparative bioavailability study, whereas the EMA requires both single- and multipledose studies. The objective of this paper is to identify the most appropriate bioequivalence metrics for paliperidone palmitate LAI products that would recognize $\mathrm{PK}$ differences which could adversely impact patients who either receive inadequate or excessive exposure to antipsychotic medication. Additionally, this paper assesses the current international bioequivalence guidelines for multiphasic products to determine whether any gaps exist when applied to new paliperidone palmitate LAI formulations being tested against the Canadian Reference Product PP1M formulation.

\section{CORRELATION BETWEEN PLASMA CONCENTRATION AND THERAPEUTIC EFFECT}

The relationship between symptom control and PK profile of PP1M has been demonstrated in two studies which compared the plasma concentration and efficacy in patients treated with PP1M or risperidone LAI (i.e. RISPERDAL CONSTA $^{\circledR}$ ) $(12,19)$. A different initiation dosing regimen for PP1M was used in each study while the dose of risperidone LAI remained the same. The Positive and Negative Syndrome Scale (PANSS) was used to measure efficacy; a validated scale that measures specific domains of schizophrenia $(20,21)$.

The first study used the lower dose initiation regimen of PP1M (50 $\mathrm{mg}$ on day 1 , and $50 \mathrm{mg}$ on day 8; both administered using the gluteal muscle), resulting in a delay in the onset of efficacy and a less pronounced overall reduction in the PANSS score as compared to risperidone LAI. The delay in onset of efficacy for PP1M was associated with the delay in the attainment of therapeutic plasma concentrations with this initiation regimen. Consistent with sub- optimal plasma concentrations, the PP1M treated patients had a higher rate of discontinuation due to lack of efficacy, a lower responder rate, and less improvement in symptom severity (19).

In the second study which used the current monograph recommended dosing regimen of PP1M (150 $\mathrm{mg}$ on day 1 and $100 \mathrm{mg}$ on day 8; both administered using the deltoid muscle), a statistically significant reduction in the PANSS total score was observed by day 4 and continued to be reduced on days 15 and 22. This supports an early onset of efficacy, without the need for oral supplementation. In contrast, the other long acting injectables risperidone (RISPERDAL $\mathrm{CONSTA}^{\circledR}$ ) and aripiprazole (ABILIFY MAINTENA ${ }^{\circledR}$ ) require supplementation with oral medications to attain efficacious plasma concentrations early in treatment (12).

Taken together, these studies demonstrate the relationship between plasma concentrations and efficacy with these long-acting injectable formulations. This early onset of efficacy is further supported in another analysis that looked at the response in the individual symptom domains of the PANSS (22). It was observed that the onset of response appeared to vary by symptom domain and may be partially driven by the change seen in uncontrolled hostility/excitement; a domain of the PANSS important for patient management (22). These results further support the relationship between PP1M plasma concentrations and onset of symptom control and efficacy $(12,19)$. If a new paliperidone palmitate LAI formulation is developed with a different PK profile, it is possible that the time to observed efficacy would also be altered.

\section{BIPHASIC RELEASE PROFILE OF PP1M}

The release of paliperidone from PP1M is characterized by a biphasic release profile: an initial zero-order release phase (i.e., the same amount of drug is released per day) during the first two weeks, and a subsequent first-order release phase (i.e., the amount released per day diminishes, proportionally to the amount left at the injection site) thereafter. Because absorption is rate-limited by its dissolution in the fluids at the injection site, PP1M exhibits "flip- flop kinetics", whereby the apparent half-life $\left(t_{1} / 2\right)$ is controlled by the absorption rate constant, $\mathrm{k}_{\mathrm{a}}(11)$.

PP1M has an extremely low water solubility and thus dissolves slowly at the site of injection. Subsequently, PP1M, is hydrolyzed by esterases in 
the muscle tissue and absorbed into the systemic circulation as paliperidone. After an initial zeroorder release phase, there is an apparent plateau at about day 15 , followed by a mono-exponential decay, visible as a straight line on this semi-log scale as seen in Figure 1 (11).

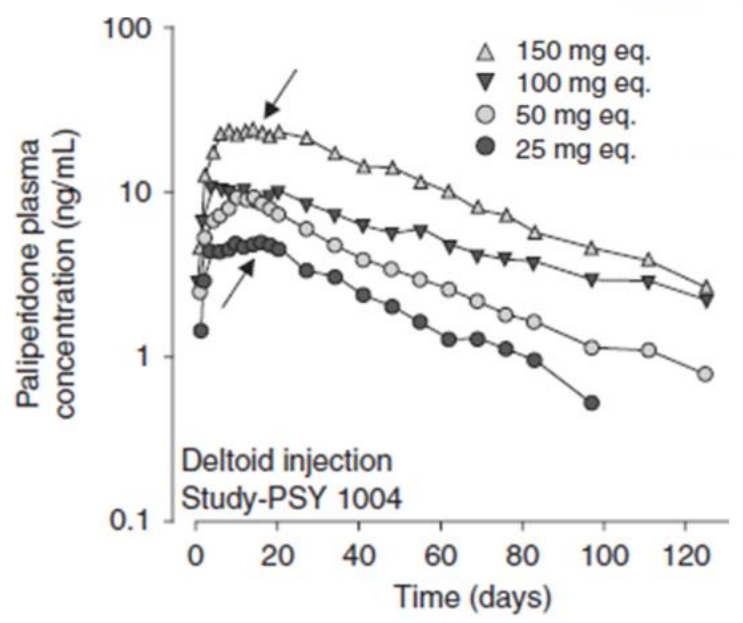

Figure 1. Logarithmic plot of mean concentration-time profiles for single IM doses of PP1M via the deltoid muscle on day 0 . Arrows indicate pharmacokinetic profiles reached an apparent plateau by day 15 (11). Reprinted by permission from Springer Nature Customer Service Centre GmbH: Springer Nature, Clinical Pharmacokinetics, Population Pharmacokinetics of Intramuscular Paliperidone Palmitate in Patients with Schizophrenia, Mahesh N. Samtani, An Vermeulen, Kim Stuyckens, Adis Data Information BV, (2009).

A population PK model that was based on pooled data from 1795 subjects in 6 phase I, 1 phase II, and 4 phase III trials determined a complex biphasic release pattern of PP1M (11). The absorption was modeled with a dual input process; where a fraction of the drug entered relatively quickly via a zero-order process and after a certain lag-time, the remaining fraction of the drug then entered the systemic circulation via a first-order process. This model estimated that approximately $17 \%$ of the administered drug entered the systemic circulation via a relatively fast zero-order input over the first 13 days, and the remainder of the drug entered after a lag time into the circulation via a slower firstorder process.

\section{EFFECTS OF MANUFACTURING PROCESSES ON THE PK PROFILE OF PP1M} As mentioned above, the rate-limiting factor for the absorption of paliperidone into the systemic circulation is the dissolution of the paliperidone palmitate at the site of injection. This is largely determined by the particle size of PP1M. In this regard, particle size drives the release rate, with smaller particles (smaller volume and larger surface area) dissolving faster.

The particle size distribution and particle morphology of PPIM is determined by operating conditions used to manufacture the final product. A key step in the manufacture of PP1M is the wet milling of the palmitate ester of paliperidone (prodrug) into an aqueous nanosuspension, with nanocrystals being approximately tenfold smaller than particles found in the standard drug powder. Undoubtedly, using a different technology and milling procedure could result in a different particle size distribution and morphology.

The effects of different manufacturing processes on the PK profile of paliperidone palmitate formulations were assessed during early development studies for PP1M. Figure 2 shows a series of different median PK profiles using a 50 $\mathrm{mg}$ strength with formulations of different particle sizes, which resulted from variations in the manufacturing process. The particle sizes of the four paliperidone palmitate formulations decreased in size from extra slow which has the largest particle size to fast which has the smallest particle size; i.e. extra slow $>$ slow $>$ marketed $>$ fast. It is clear that particle size had a considerable effect on the PK profile of paliperidone palmitate.

It is essential to note that this effect is not dose related as all subjects received $50 \mathrm{mg}$. Thus, the PK profile is reflective of the milling process (or manipulation) of the particle size. Furthermore, no dose adjustment of a formulation having different particle sizes could compensate for the differences in the PK profile. This is because changes in particle size independently affect the initial increase in plasma concentration as well as the concentration at the end of the 28-day dosing interval (see Figure 2). In other words, changing the particle size affects the initial release rate, with smaller particles (smaller volume and larger surface area) dissolving faster compared to a formulation having a larger particle size. Furthermore, with increasing particle size, the maximum observed concentration $\left(\mathrm{C}_{\max }\right)$ decreases and the time when $\mathrm{C}_{\max }$ is reached $\left(\mathrm{T}_{\max }\right)$ increases (see Figure 2). Without suitable controls on these 


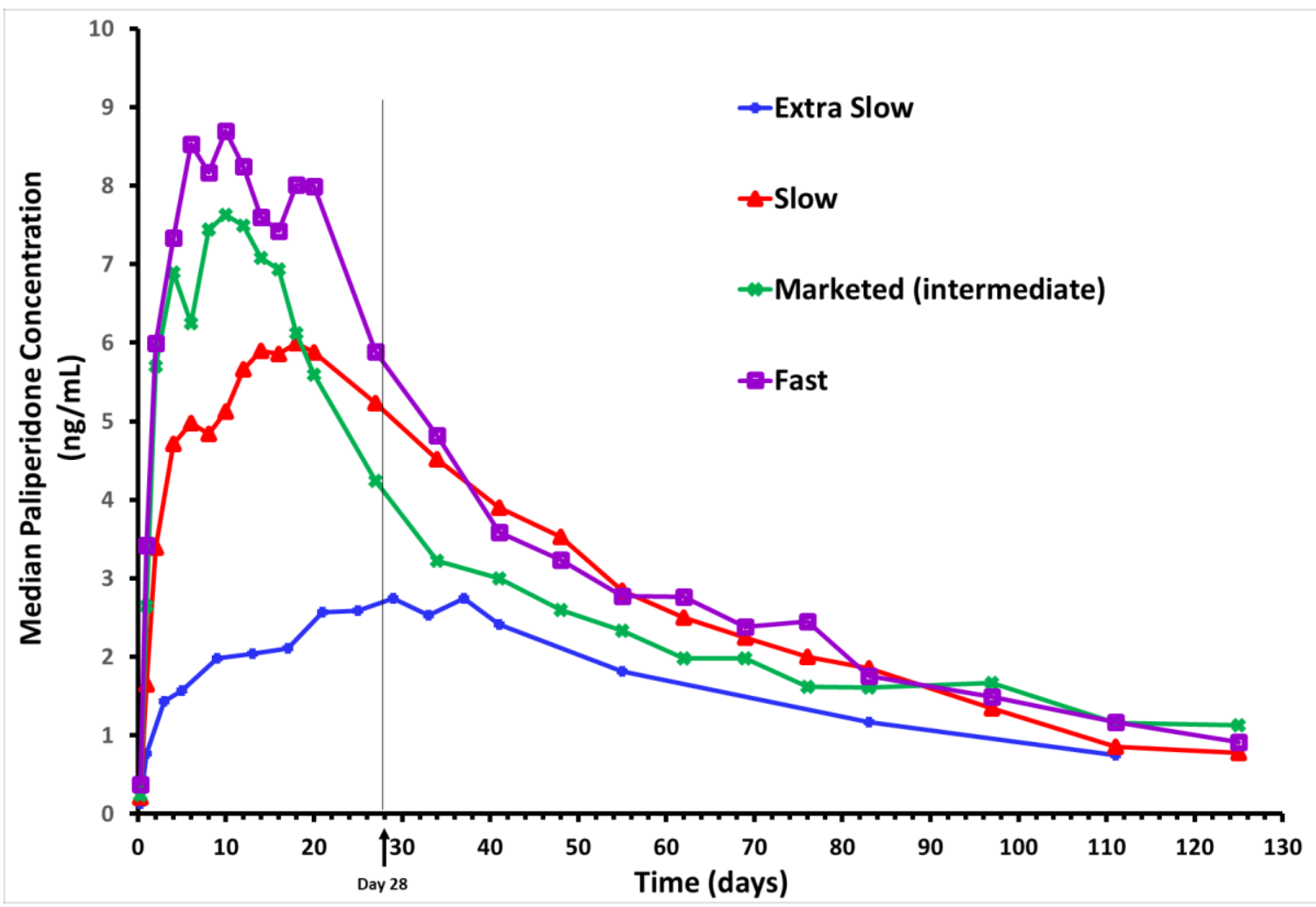

Figure 2. Data on file from PSY-1002 Randomized, open-label, parallel-group study (paliperidone palmitate $50 \mathrm{mg}$ ) to explore the in vitro/in vivo correlation of paliperidone palmitate formulations after a single IM gluteal injection. Day 28 marks when the next dose would be expected to be administered (9).

manufacturing processes, the rate of release of paliperidone from the IM injection site with a new formulation of a paliperidone palmitate LAI product could result in substantial PK differences from the Canadian Reference Product that could, in turn, impact efficacy and patient tolerability.

\section{ZERO-ORDER RELEASE PHASE - POTENTIAL CLINICAL CONSEQUENCES OF FORMULATION CHANGES ALTERING THE PK PROFILE OF PP1M}

\section{Inadequate Paliperidone Delivery; e.g. "slow" or "extra slow"}

If a new formulation of a paliperidone palmitate LAI product was produced under manufacturing conditions that altered the systemic exposure of paliperidone in a manner similar to the "slow" or "extra slow" formulation in Figure 2, this could delay the time to reach therapeutic plasma concentrations as seen in the first few days with PP1M. In other words, patients initiated on a new formulation of a paliperidone palmitate LAI product, whether a subsequent-entry (generic) product or a reformulated first-entry (brand) product, possessing a slower or delayed rate of paliperidone release could experience subtherapeutic paliperidone plasma concentrations and thus compromise clinical outcome. From a clinical perspective, subtherapeutic plasma concentrations of antipsychotic treatment have resulted in higher rates of relapse and hospitalization $(23,24)$. Consequently, relapse in and of itself is associated with: 1) significant impairment in social and vocational functioning, 2) caregiver burden, 3) hospitalization, and 4) increase the risk of suicidal and violent behaviors (7).

Given that the approved dosing regimen for PP1M does not include oral supplementation, a delayed rate of release with a new formulation of a paliperidone palmitate LAI product might result in subtherapeutic drug plasma concentrations for days after initiating treatment. However, in the case of patients stabilized on PP1M and switched to a new formulation of a paliperidone palmitate LAI product with a delayed rate of release, the clinical consequences may not become evident until after several dosing intervals, due to the long apparent $t \frac{1}{2}$ of paliperidone palmitate LAIs. 


\section{Rapid Rate or Excessive Paliperidone Delivery; e.g., "fast"}

In contrast to the previous scenario, it is also possible that under different manufacturing conditions, a new formulation of a paliperidone palmitate LAI product, whether a subsequent-entry (generic) product or a reformulated first-entry (brand) product, might also produce a faster rate of paliperidone release resembling the "fast" developmental example shown earlier in Figure 2. Short excursions above the therapeutic plasma concentration of paliperidone could result in clinically meaningful adverse events including sedation, QT prolongation, tachycardia, hypotension, hyperprolactinemia, and extrapyramidal symptoms (EPS).

Although the potential of EPS is lower with second-generation antipsychotics relative to the firstgeneration antipsychotics, it can occur at higher plasma concentrations (25). To illustrate this point, a pharmacodynamic model was developed to assess the risk of EPS at average steady-state plasma concentrations of paliperidone. The model was based on data from studies with a six-week treatment period using fixed oral doses of paliperidone and revealed a steep concentration-response profile for EPS with paliperidone extended-release (ER) (26). The risk of EPS resembled that of placebo, when the plasma concentrations were below $20 \mathrm{ng} / \mathrm{mL}$. As the steadystate plasma concentration was increased, in the range of 20 and $40 \mathrm{ng} / \mathrm{mL}$, the risk of EPS increased to maximum level with a factor of about 2.8 (relative to placebo). This is clinically relevant as individuals who develop pseudo-parkinsonism during acute treatment are less likely to respond to the treatment (27). Thus, a new formulation of a paliperidone palmitate LAI product with even small deviations in plasma profile (owing to a different manufacturing process) from the Canadian Reference Product could substantially increase the risk of clinically meaningful adverse experiences

\section{FIRST ORDER RELEASE PHASE -POTENTIAL CLINICAL CONSEQUENCES OF FORMULATION CHANGES ALTERING THE PK PROFILE OF PPIM}

Maintaining the plasma concentration within the therapeutic range until the next dose is administered is also important. Changes in manufacturing procedures that impact the particle size distribution could potentially lead to changes to the absorption rate of paliperidone resulting in the plasma concentrations dropping below the therapeutic range before the next dose is administered, or conversely, resulting in higher plasma concentrations when the next dose is administered.
Differences in the first-order release phase with a new formulation of a paliperidone palmitate LAI product also has potential ramifications when switching between products. A 2016 systemic review of data looking at the clinical and pharmacological aspects of bioequivalence for antipsychotic and antidepressants suggests that healthcare professionals should monitor patients for a few weeks after conversion to a generic product to identify if there is a deterioration of the patient's clinical state or if serious adverse events occur and evaluate if a dose adjustment is required and/or if the reference product should be reintroduced (28). It is important to ensure that a new formulation of a paliperidone palmitate LAI product does not release substantially less drug over the dosing interval, and to ensure similar trough levels of paliperidone in order to maintain the 4-week dosing interval. Thus, the first-order release phase of PP1M is important to ensure that a stable, safe, and effective therapeutic plasma concentration is maintained over the entire dosing interval.

\section{EMA \& U.S. FDA PRODUCT SPECIFIC GUIDELINES}

Considering the complex biphasic PK profile of PP1M and the potential clinical consequences of a new formulation of a paliperidone palmitate LAI product possessing a different particle size, it is important to ensure that any changes in formulation result in a therapeutically equivalent product. To this end, it is interesting to note that the approaches used to ensure that bioequivalence is a suitable predictor of therapeutic equivalence are not harmonized across regulatory jurisdictions. Both EMA and U.S. FDA have issued product-specific bioequivalence guidelines for new formulations of a paliperidone palmitate LAI product; however, these guidelines do not align on specific requirements. Although both EMA and U.S. FDA require a multiple-dose study to demonstrate bioequivalence, which would support switching between formulations at steady-state $(17,18)$, the EMA guideline also requires a singledose study. In addition, the EMA guidelines have been adopted by the Therapeutic Goods Administration of Australia which is one of the health regulatory agencies within the Australia, Canada, Singapore, Switzerland Consortium whose focus of regulatory work sharing initiatives include generic medicines (29). A comparative summary of the EMA, U.S. FDA, and Canadian guidelines, and definitions of the pharmacokinetic parameters, is provided in the Supplementary Material and a brief overview of the guidelines is provided below. 
Of interest, the draft EMA guideline dated Aug. 1, 2016 was more closely aligned to the U.S. FDA requirements than the Adopted EMA Guideline (Effective: Sept. 1, 2017) $(18,30)$. However, the EMA guideline underwent an important revision following stakeholder consultation, with the original requirements being augmented to include a singledose bioequivalence study, in addition to the multiple-dose study required in the earlier version. The following excerpt from the Committee for Medicinal Products for Human Use (CHMP) response to stakeholder comments on the draft guidance provides some background on the EMA requirement to conduct single-dose bioequivalence studies (31):

"Acknowledged that single-dose studies in patients stabilized on other antipsychotic drugs are possible to conduct

Differences in the initial release phase may be of importance for efficacy and safety at least for initial treatment and after switching from oral paliperidone

- It is uncertain if a multiple-dose bioequivalence study will be able to detect a clinically relevant difference in the absorption rate. As a precautionary measure, it is agreed that waiving of a single-dose bioequivalence study is not recommended."

The parameters required by the EMA for the analysis of the single-dose study include $\mathrm{C}_{\max }$, $\mathrm{AUC}_{\text {inf }}$, and $\mathrm{AUC}_{0-\mathrm{t}}$ with the addition of $\mathrm{T}_{\max }$ (median and range). The addition of $\mathrm{T}_{\max }$ is to determine whether a relevant difference in the rate of absorption and lag time is observed.

For the multiple-dose studies, both agencies allow either crossover or parallel designs, conducted in patients with schizophrenia or schizoaffective disorder. However, the EMA guideline permits studies in patients stabilized on another antipsychotic medication, while the U.S. FDA recommends against this practice. Only the U.S. FDA guideline indicates that both the gluteal and deltoid sites of injection are to be included in the study design. The dosage strengths recommended for bioequivalence studies also differ, with the EMA allowing any strength to be used, provided the test product has the same concentration of active substance as the reference for all the strengths. Although, the U.S. FDA also allows in vivo testing of a single dosage strength and a waiver of testing for the remaining strengths, the U.S. FDA guideline specifies that an acceptable bioequivalence study must be completed with the 156 $\mathrm{mg} / \mathrm{mL}$ strength (i.e. $100 \mathrm{mg}$ eq. paliperidone). ${ }^{1}$

Both the EMA and U.S. FDA require determination of the peak $\left(\mathrm{C}_{\max , \mathrm{ss}}\right.$ and $\mathrm{C}_{\max }$ ss, respectively) and trough $\left(\mathrm{C}_{\tau, \mathrm{ss}}\right.$ and $\mathrm{C}_{\min } \mathrm{ss}$, respectively) levels at steady-state, as well as the area under the curve during a dosing interval at steady-state $\left(\mathrm{AUC}_{0-\tau}\right.$ and $\mathrm{AUC}_{\tau}$, respectively). The only major difference is the U.S. FDA's requirement for a fluctuation term as part of the multiple-dose assessment where the actual parameters must fall within the $80-125 \%$ range for determination of bioequivalence.

\section{RELEVANT CANADIAN GUIDANCE}

There are no product-specific guidance documents for modified-release injectable dosage forms, including PP1M, in Canada. Although only the branded PP1M, INVEGA SUSTENNA ${ }^{\circledR}$, is currently available in the Canadian market, it is not transparent what PK metrics Health Canada would apply to a new formulation of a paliperidone palmitate LAI product referencing INVEGA SUSTENNA ${ }^{\circledR}$. Health Canada recently revised the Canadian regulatory requirements for oral dosage formulations recognizing additional metrics are needed to ensure bioequivalence of more complex products; however, like the previous version, the revised guidance specifically excludes injectable IM/SC products from its scope (16). The 1990 policy on Submissions for Generic Parenteral Drugs includes the requirement for "clinical trials establishing safety and effectiveness of the product" (32). Being a suspension, it would appear that PPIM

\footnotetext{
1. For international comparisons, Canadian and European doses are based on paliperidone, whereas U.S. doses are based on paliperidone palmitate. The syringes contain $25 \mathrm{mg} / 0.25 \mathrm{~mL}, 50 \mathrm{mg} / 0.5 \mathrm{~mL}, 75 \mathrm{mg} / 0.75 \mathrm{~mL}, 100 \mathrm{mg} / 1 \mathrm{~mL}$ or $150 \mathrm{mg} / 1.5 \mathrm{~mL}$ paliperidone [as 39,78 , 117, 156 or $234 \mathrm{mg}$ of paliperidone palmitate, respectively]. Canadian and European doses are sometimes described as "paliperidone palmitate equivalent to paliperidone" e.g. $150 \mathrm{mg}$ eq. Paliperidone. Thus, the U.S. initiation regimen is identical to Canadian and European regimens but is described in terms of paliperidone palmitate as $234 \mathrm{mg}$ on treatment day 1 and $156 \mathrm{mg}$ for the second injection.
} 
would fall in Category IV and that the only guidance is "a written opinion on special requirements for individual products will be provided on request..." as noted in the table in the Supplementary Material. Development of specific guidance for modified-release injectable dosage forms would appear consistent with Health Canada's Regulatory Transparency and Openness Framework and Action Plan as it outlines a commitment to "Make coherent, targeted efforts to help industry fulfill their responsibilities to provide safe and effective products by providing upto-date information and guidance" (33).

The lack of guidance in Canada in the area of oral modified-release products with multiphasic plasma concentration profiles linked to product efficacy has already been seen in the area of Attention-deficit/hyperactivity disorder (ADHD). In this case, some patients saw their condition destabilize once they were switched from OROS $^{\circledR}$ methylphenidate to another listed bioequivalent generic methylphenidate product $(34,35)$. In the United States, the FDA became concerned about generic methylphenidate products that may not be therapeutically equivalent to the reference product after receiving reports from patients indicating a lack of effect (36). The U.S. FDA identified two generic methylphenidate products that had insufficient data to determine therapeutic equivalence with the reference product. As such, the FDA requested that data be provided to confirm they meet the revised measures put in place for bioequivalence testing for methylphenidate hydrochloride ER tablets $(37,38)$. As noted earlier, Health Canada has recently revised the Canadian regulatory requirements for oral and non-injectable formulations and included the measurement of partial AUC (pAUC) for modified- release dosage forms. However, unlike the direction taken by the U.S. FDA, the requirement to meet the revised measure (i.e. pAUC) has not been implemented in Canada for existing marketed methylphenidate hydrochloride ER products. Had additional PK metrics, such as pAUC, been considered when subsequent-entry methylphenidate ER products were first evaluated, differences in PK parameters and bioequivalence between formulations might have been observed (39). The need for the addition of pAUC metrics to discriminate between modifiedrelease products has been implemented by the U.S.
FDA for other medications as well; e.g., zolpidem ER, dexmethylphenidate, mixed amphetamine salts, mesalamine, methylphenidate hydrochloride ER suspension, naltrexone ER IM, octreotide acetate, triptorelin pamoate, and budesonide (40).

There are proposed changes in Canada where a declaration of equivalence could be given to a subsequent-entry IV product that is a different salt form of the medicinal ingredient as long as the therapeutically active component is chemically identical to the reference product $(14,15)$. However, a recent review highlights the impact that a chosen salt form can have on the physiochemical and biological properties of the active pharmaceutical ingredients (41). In this regard, the salt form chosen can impact the drug's polymorphism, solubility, particle size, stability of formulation, as well as other criteria that have an effect on the physiochemical properties which can influence the release of the product. In contrast to different salt forms, the draft guidance in Canada currently does not consider subsequent-entry (generic) products with different esters eligible to be filed via the Abbreviated New Drug Submissions regulatory pathway. This component of the guidance is consistent with earlier data on the clinical pharmacokinetics of depot antipsychotics, which indicated that the use of different esters in a formulation can result in a change in the plasma concentration-time profile (42). For example, the time to reach peak plasma concentrations of fluphenazine, a depot antipsychotic, was seen to be different between the decanoate and enanthate ester forms (42). Fluphenazine decanoate was shown to reach peak concentrations earlier than fluphenazine enanthate and the appearance of EPS was also seen to occur earlier with the decanoate form in a timeframe that corresponded to the observation of peak plasma levels (42). Taking this evidence into account, new formulations of a paliperidone palmitate LAI product with a different ester of the medicinal ingredient would also need to be carefully evaluated to determine whether changes to the ester moiety impact the plasma concentration-time profile, which in turn could impact the patient outcomes. The known examples of situations where a change in the 
salt form of the medicinal ingredient can affect a compound's physiochemical and biological properties, raise questions about the divergent approaches proposed for determination= of equivalence of molecular entities with different salts versus those having different esters.

Establishing clear, transparent standards for new formulations of paliperidone palmitate LAI products in Canada, whether this is a stand-alone guidance or a revision to the existing guidance for oral and noninjectable formulations to include multiphasic and biphasic IM/SC products, would be consistent with Health Canada's initiative around regulatory openness and transparency by providing up-to-date information and guidance to industry to ensure Canadians are provided with safe health products. If the bioequivalence standards are less than optimal to ensure that products deemed interchangeable are truly therapeutic equivalents, then the undetected differences in PK profiles could result in clinically important differences in safety and efficacy and impact patient outcomes.

\section{PROPOSAL FOR CANADIAN BIOEQUIVALENCE STANDARD FOR LAIS}

\section{Multiple-dose bioequivalence studies to be required to demonstrate bioequivalence of PP1M products in Canada}

As noted earlier, EMA and U.S. FDA guidelines require a multiple-dose study to demonstrate bioequivalence for new formulations of a paliperidone palmitate LAI product. The current Health Canada guidance indicates that steady-state studies for oral modified-release products are generally not required and as noted earlier there is no stated guidance for modified-release injectable dosage forms. However, the guidance document on conducting comparative bioavailability studies states the following when designing such studies: "A crossover design without a drug-free period between formulations may be employed for studies conducted in patients in whom it would be unethical to discontinue treatment during a washout period. Instead of a drug-free washout period, the study drugs are administered long enough, prior to sampling, to allow elimination of the previously administered formulation" (43).

For paliperidone palmitate LAI products, multiple-dose studies could assist in assessing bioequivalence by determining any fluctuations in concentration during the first-order release phase.
Endrenyi and Tothfalusi outlined the importance of considering multiple-dose studies to assist with ensuring therapeutic equivalence when different release characteristics of two products would be amplified at steady-state (44). Bois et al. evaluated several approaches to measure the rate of absorption using simulations in single-dose studies and concluded that the current rate measures are not sensitive enough to detect a $25 \%$ difference in the absorption rate constant, $\mathrm{k}_{\mathrm{a}}$. Furthermore, looking specifically at $\mathrm{C}_{\max }$, they noted that even differences in the absorption rate above $25 \%$ are not observed due to the low sensitivity of $\mathrm{C}_{\max }$ (45). The zeroorder and first-order release phases of PP1M are independent of each other; thus it is likely that a single-dose study would not have the sensitivity to detect differences in PK parameters that are governed by the particle size distribution in the product formula.

To investigate this possibility, a switching scenario was simulated to determine whether a product with altered release properties but the same $\mathrm{C}_{\max }$ and AUC (after single dosing) could, upon switching, alter the pharmacokinetic profile during subsequent dosing cycles (46). This simulation was performed using the validated PP1M population PK model. The simulation pictured in Figure 3 for products with the same $\mathrm{C}_{\max }$ and AUC (after a single dose), but with a lower first-order release rate (characterized by the absorption rate constant, $\mathrm{k}_{\mathrm{a}}$ ), demonstrates significant differences in $\mathrm{C}_{\min }(-24 \%$ to $-69 \%$ ) that could potentially impact clinical effectiveness after subsequent dosing cycles.

A switching study (such as a steady-state crossover study) may also enable detection of differences in absorption rate secondary to modified formulations such as injection volume, as well as site of administration, provided that transient $\mathrm{C}_{\min }, \mathrm{C}_{\max }$ and $\mathrm{AUC}_{\text {tau }}$ are thoroughly evaluated by extensive PK sampling during early dosing intervals after the switch (see Figure 3). This simulation demonstrates that switching can result in significant changes in the systemic drug concentrations for a prolonged time period after switching. A lower $\mathrm{C}_{\min }$ results in less exposure that can put patients at risk for relapse if they are below the therapeutic plasma concentration. Conversely, the effect of a faster rate of absorption of a new formulation of a paliperidone palmitate LAI product compared to PP1M could increase the risk of clinically meaningful adverse experiences.

Frequent early sampling after a switch to ensure steady state has been reached is consistent with the recommendation in the U.S. FDA product-specific 


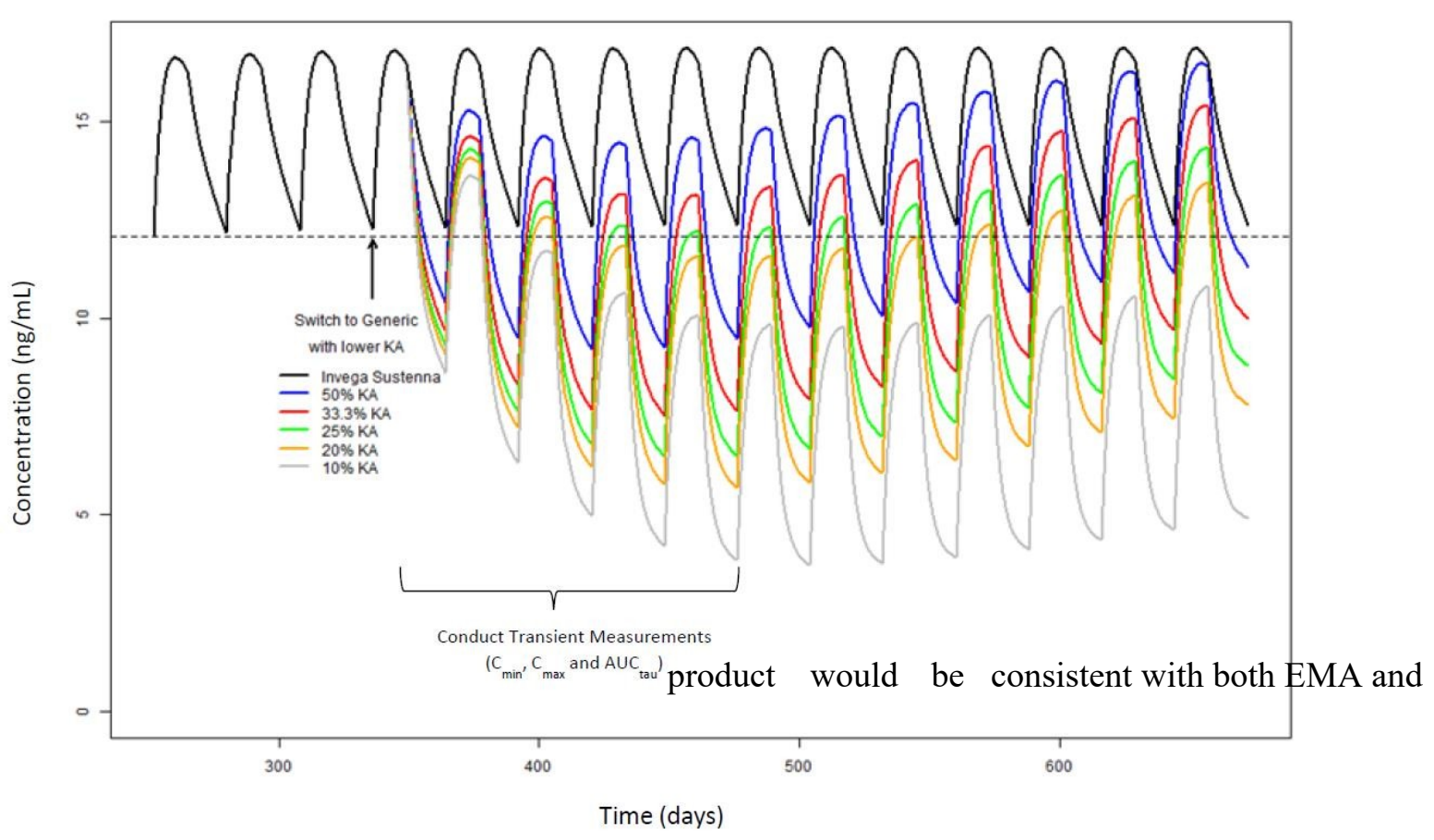

Figure 3. Concentration-time Profile upon Switching from PP1M to another Paliperidone Palmitate LAI Product with Lower Absorption Rate Constant $\left(\mathrm{k}_{\mathrm{a}}\right)$. KA is a percentage of $\mathrm{k}_{\mathrm{a}}$ of INVEGA SUSTENNA ${ }^{\circledR}(46)$.

guideline on Paliperidone Palmitate, Extended Release Suspension, Intramuscular that " $P K$ data should be submitted to demonstrate that steady state has been reached for each individual." (17). Application of a multiple-dose study to determine the bioequivalence of a new formulation of a paliperidone palmitate LAI product would be consistent with both EMA and U.S. FDA produc-specific guidelines. Thus, a switching study would allow for detection of differences in $k_{a}$ that could be amplified in steady-state when a patient is switched from the Canadian Reference Product to a new formulation of a paliperidone palmitate LAI product.

However, a multiple-dose study is unlikely to detect changes in the initial zero-order release phase which is important for patients initiating treatment or switching from oral paliperidone as there is no oral supplementation with PP1M. A delayed rate of release with a new formulation of a paliperidone palmitate LAI product might result in subtherapeutic paliperidone plasma concentrations for days after a patient has been initiated on treatment. Thus, a single-dose study is also recommended.

\section{Single-dose bioequivalence studies incorpo- rating partial AUC metrics to be required to demonstrate bioequivalence of PP1M products in Canada}

The EMA guidance for single-dose studies would be expected to be very effective for ensuring bioequivalence of different formulations of paliperidone palmitate LAI. However, a potential limitation is the reliance on $\mathrm{T}_{\max }$ to ensure that a new formulation of a paliperidone palmitate LAI product has a clinically comparable onset of efficacy.

Evaluating IM/SC LAI products solely on the bioequivalence criteria of $\mathrm{C}_{\max }$ and $\mathrm{AUC}$ to the last quantifiable concentration (AUCT) in the fasted and fed conditions, may not detect potentially significant and clinically meaningful differences stemming from different PK profiles of PP1M and a new formulation of a paliperidone palmitate LAI product with a different particle size distribution and/or particle morphology. The total extent of the exposure determined by these metrics (Cmax and AUCT) may be the same for two products, but the exposure during specific time intervals that are clinically relevant may not be the same, as depicted in Figure 4. 
Figure 4 shows median concentrationtime profiles of patients who received 150 mg PP1M (PSY-1004 study) and simulated profiles to demonstrate that there can be a delay in attaining therapeutic plasma concentrations, despite identical $\mathrm{C}_{\max }$ and AUC. Most noteworthy in the context of the EMA guideline is the Simulation 1 curve. Despite having an identical $\mathrm{T}_{\max }$ compared to $\mathrm{PP} 1 \mathrm{M}$, the time to attain a therapeutic level is delayed. A different concentration profile would be especially problematic if patients on PP1M were switched to a new formulation of a paliperidone palmitate LAI product with different release properties, resulting in patients undergoing periods with inadequate paliperidone release that could result in decreased efficacy and clinically significant relapses.

The recently revised Canadian guidance on comparative bioavailability standards, indicates that
"Modified-release products with multiphasic plasma concentration profiles demonstrated to be integral to their therapeutic effect will be subject to standards on the partial area under the concentration versus time curve (pAUC), defined over a restricted time interval(s) after drug administration" (16). These standards will be applied in addition to those normally applied in the assessment of bioequivalence (i.e. AUC and $\mathrm{C}_{\max }$ ). Health Canada has recognized the need for additional metrics (pAUC) for modifiedrelease products but as currently written, this guidance applies only to oral and non-injectable formulations. However, the requirements of the guidance could also be applied to the complex biphasic profile of PP1M, given the temporal relationship between plasma concentrations and clinical efficacy seen with this once monthly regimen. To illustrate, the same median concentration-time profile from Figure 4

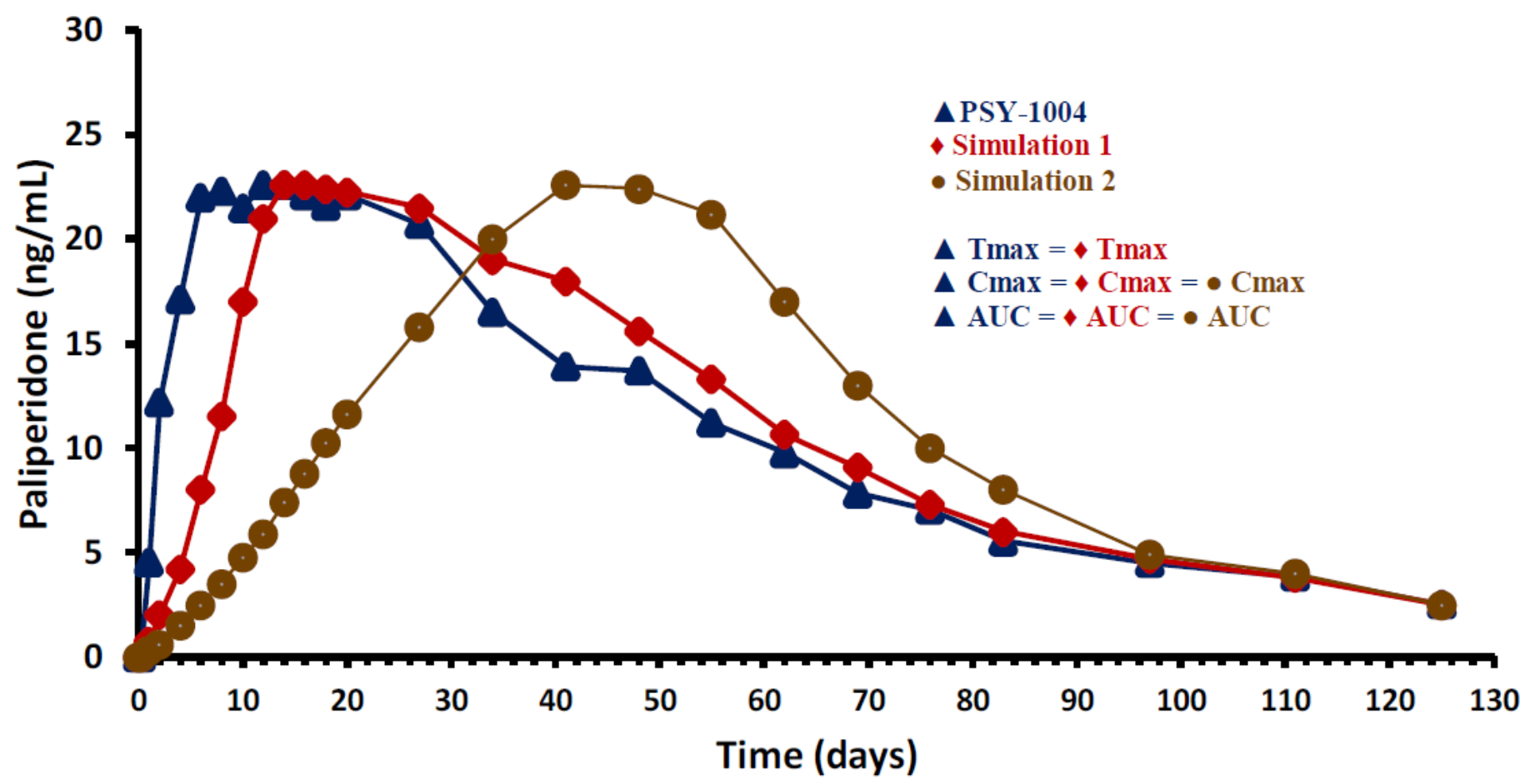

Figure 4. Median concentration-time profiles of patients who received $150 \mathrm{mg}$ PP1M and simulations 


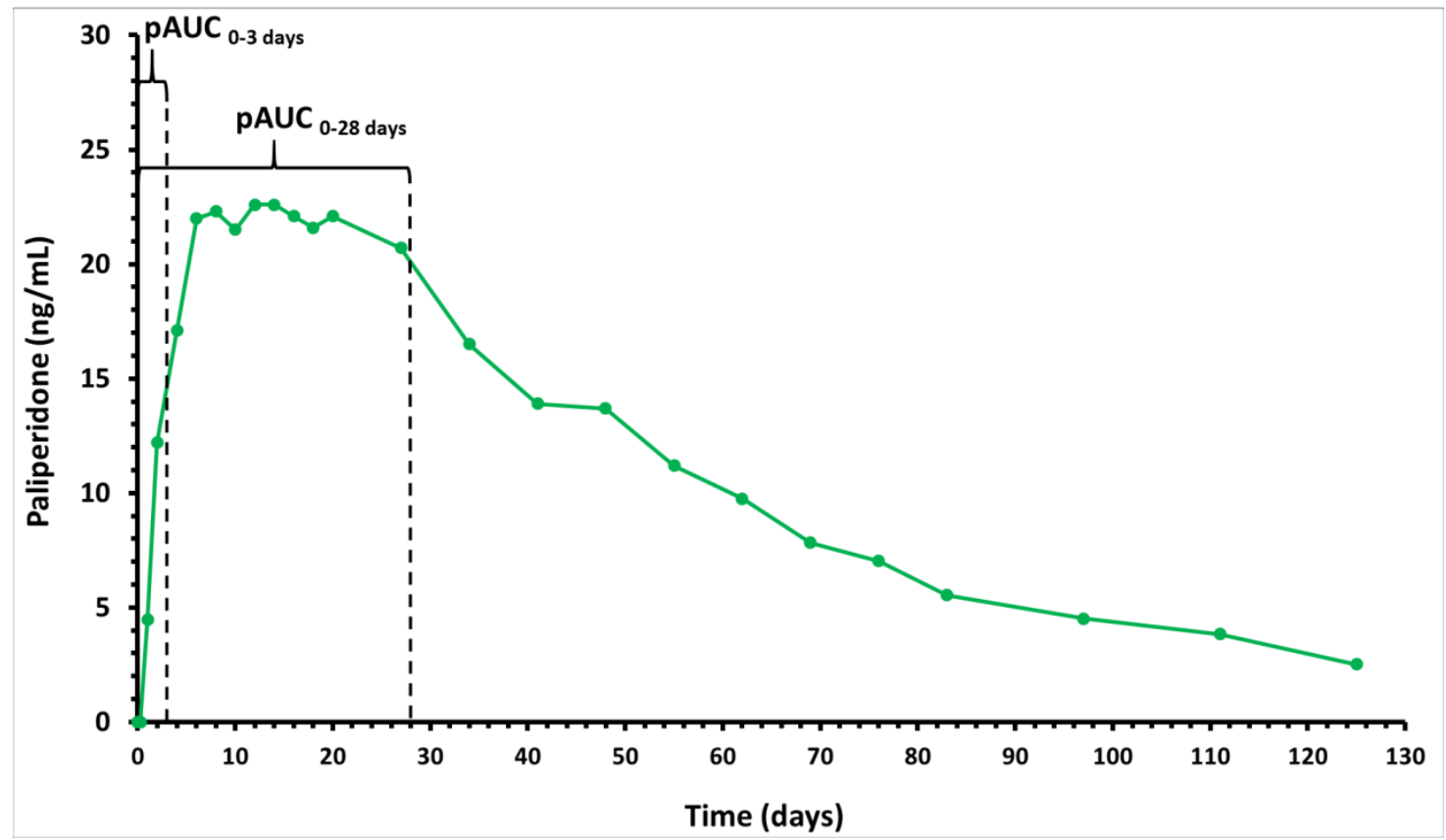

Figure 5. Mean Plasma Paliperidone PK Profile following Deltoid Muscle Administration of $150 \mathrm{mg}$ PP1M with the Proposed Bioequivalence Metrics $\mathrm{pAUC} 0-3$ days and $\mathrm{pAUC} \mathrm{Al}_{0-28 \text { days }}$

(PSY-1004) is shown in Figure 5, only this time with two proposed pAUC metrics.

As illustrated in Figure 5, inclusion of the additional bioequivalence metric of $\mathrm{pAUC}_{0-3}$ days would ensure that the plasma concentration has risen sufficiently in the first 3 days after administration to support the early onset of clinical efficacy by day 4 . This time frame is also of interest as the second dose of the recommended initiation regimen is 1 week after the initial dose. As such, this pAUC falls near the mid-point of the initiation dosing interval. Physicians using PP1M would rightfully expect to see efficacy with a new formulation of a paliperidone palmitate LAI product in a similar timeframe as PP1M, the Canadian Reference Product. However, a new formulation of a paliperidone palmitate LAI product possessing a delayed PK profile may lead a physician to conclude that the patient was unresponsive to treatment, when in fact, the lack of response may be the result of altered pharmacokinetics, (and thus bioequivalence), resulting from a varied formulation or manufacturing process of the new formulation of a paliperidone palmitate LAI product. Additionally, evaluation of early exposure would identify the potential for dose dumping.

The second metric illustrated in Figure $5, \mathrm{pAUC}_{0-28}$ days, provides a measure of the extent of paliperidone exposure by the end of the first dosing interval on day 28. The firstorder release phase is important to maintain a therapeutic plasma concentration by providing a constant release of drug until the next monthly injection.

Given the importance of these timepoints to the onset and maintenance of paliperidone plasma concentrations associated with efficacy, we recommend including the illustrated pAUC metrics (i.e., pAUC ${ }_{0-3}$ days, $\mathrm{pAUC}_{0-28}$ days) in the assessment of bioequivalence of a new formulation of a paliperidone palmitate LAI product to a Canadian Reference Product PP1M formulation. The first ensures the early increase in plasma concentrations, which is closely linked to the onset of efficacy, and the second ensures plasma concentrations are adequately maintained within the therapeutic range until the next dose is administered. The use of pAUCs is consistent with Health Canada's recent modification to bioequivalence standards for oral dosage forms of multiphasic modifiedrelease products that have plasma concentration profiles that are integral to their therapeutic effects. 
Based on the results of simulations, it is believed that pAUC metrics would be more reliable in ensuring therapeutic equivalence of these complex LAI products than $\mathrm{T}_{\max }$.

\section{SUMMARY}

LAI formulations are important for ensuring adherence in patients with schizophrenia. Studies have shown that there is a positive impact to patient adherence and persistence with PP1M versus oral atypical antipsychotic therapy.

PP1M's efficacy is closely related to its biphasic PK profile. PP1M is designed for rapid attainment of therapeutic plasma concentration without the need for oral supplementation, and for maintaining therapeutic plasma concentrations until the next dose is administered. Technology and operating conditions used in the manufacturing of paliperidone palmitate LAI products can affect the nanoparticle size distribution, which can in turn alter the release rate, and ultimately PK profile. Changes affecting the PK profile of a new formulation of a paliperidone palmitate LAI product could potentially have clinical consequences, including increased risk of adverse events or, even worse, relapse.

Health Canada has already recognized the need for additional metrics (i.e., pAUC) for modifiedrelease products. Requiring pAUC as a prerequisite to assess bioequivalence would ensure that new formulations of paliperidone palmitate LAI products manufactured with potentially different technologies are bioequivalent to the Canadian Reference Product PP1M formulation during both the initiation treatment period (measured by $\mathrm{pAUC}_{0-3}$ days) and over the entire dosing interval (measured by $\mathrm{pAUC}_{0-28 \text { days). }}$ ). Furthermore, multiple-dose studies would serve to ensure that patients would not be exposed to subtherapeutic paliperidone concentrations for a period of time after switching from the Canadian Reference Product, which could result in destabilization and relapse. The introduction of prescriptive new standards in Canada (see Recommendations) to determine the bioequivalence of paliperidone palmitate LAIs would be a significant step towards ensuring new formulations of a paliperidone palmitate LAI product are therapeutically equivalent allowing patients to receive the full benefits of the medication whether this is a newly diagnosed patient, or a patient already stabilized on therapy.

\section{RECOMMENDATIONS}

- It is recommended that the EMA and U.S. FDA product specific guidelines for paliperidone palmitate LAI be used as the basis for Canadian standards to ensure therapeutic equivalence when switching between formulations at steady- state

- It is recommended that Canada use bioequivalence standards similar to those in the EMA, which require a single-dose study, in addition to a multiple-dose study

- It is recommended to replace the requirement for $\mathrm{T}_{\max }$ (from the EMA guideline for the singledose study) with pAUC metrics, as it would more reliably ensure predictable and replicable plasma concentrations for patient dose responses at varying times in their treatment

- It is recommended that the following metrics be applied to new formulations of paliperidone palmitate LAI products to assess bioequivalence to the Canadian Reference Product PP1M formulation:

1. A single-dose cross-over, comparative bioavailability study, including evaluation of the following: $\mathrm{AUC}_{0-\mathrm{t}}, \mathrm{AUC}_{\mathrm{inf}}, \mathrm{C}_{\mathrm{max}}$, and the specific partial AUC metrics, (i.e., pAUC $0-3$ days and pAUC $\left.{ }_{0-28 \text { days }}\right)$ reflecting the product's biphasic PK profile;

2. A multiple-dose, cross-over, switching study, with evaluation of the following individual and mean steady-state parameters: $\mathrm{C}_{\min }, \mathrm{ss}, \mathrm{C}_{\max }, \mathrm{ss}$ and $\mathrm{AUC}_{\tau}$. Extensive sampling is recommended during early dosing intervals after switching, with monitoring of $\mathrm{C}_{\min }, \mathrm{C}_{\max }$ and $\mathrm{AUC}_{\text {tau }}$ over at least 3 dosing intervals to ensure steady-state has been attained.

For each of these parameters $\left(\mathrm{AUC}_{0-\mathrm{t}}, \mathrm{AUC}_{\mathrm{inf}}\right.$, $\mathrm{C}_{\max }, \mathrm{pAUC}_{0-3 \text { days }}, \mathrm{pAUC} \mathrm{C}_{0-28 \text { days, }} \mathrm{C}_{\min }, \mathrm{ss}, \mathrm{C}_{\max }, \mathrm{sS}$ and $\mathrm{AUC}_{\tau}$ ), it is proposed that the $90 \%$ confidence interval of the ratio of the relative means of the new formulation of paliperidone palmitate LAI product to the Canadian Reference Product PP1M formulation should fall within $80 \%-125 \%$. 


\section{CONFLICTS OF INTEREST}

R. Procyshyn has received consulting fees or sat on paid advisory boards for Janssen, Lundbeck and Otsuka; is on the speaker's bureau for Janssen, Lundbeck and Otsuka.

J. Lamoure has received lifetime speaker/advisory board fees from Eli Lilly, Sanofi Canada, JanssenOrtho, Pfizer Canada, BMS Canada, Lundbeck Canada, Pfizer, Sunovion Canada, Astra-Zeneca, Shire, Valeant Canada, Otsuka Canada, Pediapharm Canada; has received travel funding from Pfizer Canada, Lundbeck Canada; has received research funding from Eli Lilly Canada, Sanofi Canada.

M. Katzman has received research fees, speaker/advisory board fees, consulting fees, or travel funding from AstraZeneca, Biotics, Boehringer Ingelheim, Bristol-Myers Squibb, Canopy, Eli Lilly, Forrest/Actavis/Allergan, Genuine Health, Janssen, Lundbeck, Merck, Otsuka, Pfizer, Purdue, Shire, Sunovion, and Takeda; has received research grant funding from Canadian Foundation for Innovation and Lotte \& John Hecht Memorial Foundation.

P. Skinner and S. Sherman are full-time employees of Janssen Inc.

\section{REFERENCES}

1. Canadian Psychiatric Association. Clinical Practice Guidelines. Treatment of schizophrenia. Can J Psychiatry. 2005 Nov;50(13 Suppl 1):7S-57S.

2. Llorca PM. Partial compliance in schizophrenia and the impact on patient outcomes. Psychiatry Res. 2008 Nov;161(2):235-247.

DOI: 10.1016/j.psychres.2007.07.012.

3. Chen EY, Hui CL, Dunn EL, Miao MY, Yeung WS, Wong CK, et al. A prospective 3-year longitudinal study of cognitive predictors of relapse in firstepisode schizophrenic patients. Schizophr Res. 2005 Sep;77(1):99-104.

DOI: 10.1016/j.schres.2005.02.020.

4. Robinson D, Woerner MG, Alvir JM, Bilder R, Goldman R, Geisler S, et al. Predictors of relapse following response from a first episode of schizophrenia or schizoaffective disorder. Arch Gen Psychiatry. 1999 Mar;56(3):241-247. DOI: 10.1001/archpsyc.56.3.241.

5. Keith SJ, Pani L, Nick B, Emsley R, San L, Turner $M$, et al. Practical application of pharmacotherapy with long-acting risperidone for patients with schizophrenia. Psychiatr Serv. 2004 Sep;55(9):997-

1005. DOI: 10.1176/appi.ps.55.9.997.

6. Almond S, Knapp M, Francois C, Toumi M, Brugha T. Relapse in schizophrenia: costs, clinical outcomes and quality of life. $\mathrm{Br} \mathrm{J}$ Psychiatry. 2004 Apr:184:346-351. DOI: 10.1192/bjp.184.4.346.

7. Haddad PM, Brain C, Scott J. Nonadherence with antipsychotic medication in schizophrenia: challenges and management strategies. Patient Relat Outcome Meas. 2014;5:43-62. DOI: 10.2147/PROM.S42735.

8. Byerly MJ, Nakonezny PA, Lescouflair E. Antipsychotic medication adherence in schizophrenia. Psychiatr Clin North Am. 2007 Sep;30(3):437-452. DOI: 10.1016/j.psc.2007.04.002.

9. Janssen Inc. INVEGA SUSTENNA ${ }^{\circledR}$ Product Monograph [Internet]. Toronto: The Company; 2018 [cited 2019 Apr]. Available from: https://www.janssen.com/canada/sites/www janssen com_canada/files/prod files/live/invega sustenna cpm.pdf

10. Janssen Inc. INVEGA TRINZA ${ }^{\circledR}$ Product Monograph [Internet]. Toronto: The Company; 2018 [cited 2019 Apr]. Available from: https://www.janssen.com/canada/sites/www janssen com canada/files/prod files/live/invega trinza $\mathrm{cp}$ m.pdf

11. Samtani MN, Vermeulen A, Stuyckens K. Population pharmacokinetics of intramuscular paliperidone palmitate in patients with schizophrenia: a novel once-monthly, long-acting formulation of an atypical antipsychotic. Clin Pharmacokinet. 2009;48(9):585600. DOI: $10.2165 / 11316870-000000000-00000$.

12. Fu DJ, Bossie CA, Kern Sliwa J, Ma YW, Alphs L. Paliperidone palmitate versus risperidone long-acting injection in markedly-to-severely ill schizophrenia subjects: onset of efficacy with recommended initiation regimens. Clin Schizophr Relat Psychoses. 2014 Jul;8(2):101-109A. DOI: 10.3371/CSRP.FUBO.022213.

13. U.S. Food and Drug Administration. Approved drug products with therapeutic equivalence evaluations (orange book) [Internet]. 39th ed. Rockville: FDA Center for Drug Evaluation and Research; 2019 [cited 2019 Apr]. Available from: https://www.fda.gov/drugs/drug-approvals-anddatabases/approved-drug-products-therapeuticequivalence-evaluations-orange-book

14. Government of Canada. Canada Gazette, Part I, Volume 153, Number 13: Regulations amending the food and drug regulations (improving access to generics) [Internet]. 2019 Mar 30 [cited 2019 Apr]. Available from: http://www.gazette.gc.ca/rp$\mathrm{pr} / \mathrm{p} 1 / 2019 / 2019-03-30 / \mathrm{html} / \mathrm{reg} 2-$ eng.html

15. Health Canada. Draft Guidance Document - Generic drug equivalence: medicinal ingredients [Internet]. 2019 Apr 8 [cited 2019 May]. Available from: 
https://www.canada.ca/en/health-

canada/services/drugs-health-products/public-

involvement-consultations/drug-

products/consultation-profile-draft-generic-drug-

equivalence/document-1.html

16. Health Canada. Guidance Document - Comparative bioavailability standards: formulations used for systemic effects [Internet]. [effective 2018 Sep 1; cited 2018 Jul]. Available from: https://www.canada.ca/en/healthcanada/services/drugs-health-products/drugproducts/applications-submissions/guidancedocuments/bioavailability-

bioequivalence/comparative-bioavailabilitystandards-formulations-used-systemic-effects.html

17. U.S. Food and Drug Administration. Draft guidance on paliperidone palmitate, extended release suspension, intramuscular [Internet]. [recommended 2011 Aug; revised 2013 Dec, 2015 Dec, 2016 Jul; cited 2018 Jul]. Available from: https://www.fda.gov/downloads/Drugs/GuidanceCo mplianceRegulatoryInformation/Guidances/UCM27 0384.pdf

18. European Medicines Agency. Paliperidone palmitate depot suspension for injection $25 \mathrm{mg}, 50 \mathrm{mg}, 75 \mathrm{mg}$, $100 \mathrm{mg}$ and $150 \mathrm{mg}$ product-specific bioequivalence guidance [Internet]. [effective 2017 Sep 1; cited 2018 Jul]. Available from: http://www.ema.europa.eu/docs/en_GB/document li brary/Scientific_guideline/2017/03/WC500222375.p df

19. Fleischhacker WW, Gopal S, Lane R, GassmannMayer C, Lim P, Hough D, et al. A randomized trial of paliperidone palmitate and risperidone long-acting injectable in schizophrenia. Int J Neuropsychopharmcol. 2012 Feb;15(1):107-118. DOI: $10.1017 / \mathrm{S} 1461145711001076$.

20. Kay SR, Fiszbein A, Opler LA. The positive and negative syndrome scale (PANSS) for schizophrenia. Schizophr Bull. 1987;13(2):261-276. DOI: 10.1093/schbul/13.2.261.

21. Lindenmayer JP, Bernstein-Hyman R, Grochowski S. A new five factor model of schizophrenia. Psychiatr Q. 1994;65(4):299-322.

22. Alphs L, Bossie CA, Fu DJ, Ma YW, Kern Sliwa J. Onset and persistence of efficacy by symptom domain with long-acting injectable paliperidone palmitate in patients with schizophrenia. Expert Opin Pharmacother. 2014 May;15(7):1029-1042. DOI: 10.1517/14656566.2014.909409.

23. McCutcheon R, Beck K, D'Ambrosio E, Donocik J, Gobjila C, Jauhar S, et al. Antipsychotic plasma levels in the assessment of poor treatment response in schizophrenia. Acta Psychiatr Scand. 2018 Jan;137(1):39-46. DOI: 10.1111/acps.12825.

24. Lopez LV, Shaikh A, Merson J, Greenberg J, Suckow RF, Kane JM. Accuracy of clinician assessments of medication status in the emergency setting: a comparison of clinician assessment of antipsychotic usage and plasma level determination. J Clin Psychopharmacol. 2017 Jun;37(3):310-314. DOI: 10.1097/JCP.0000000000000697.

25. Weiden PJ. EPS profiles: the atypical antipsychotics are not all the same. J Psychiatr Pract. 2007 Jan;13(1):13-24.

26. de Ridder F, Vermeulen A, Cleton A, Kramer M, Eerdekens M. Evaluation of the Clinical relevance of the food effect observed with paliperidone ER, using a pharmacokinetic/pharmacodynamic modeling approach. Poster session presented at: 3rd Pharmaceutical Sciences World Congress (PSWC); 2007 Apr 22-25; Amsterdam, Netherlands.

27. Robinson DG, Woerner MG, Alvir JM, Geisler S, Koreen A, Sheitman B, et. al. Predictors of treatment response from a first episode of schizophrenia or schizoaffective disorder. Am J Psychiatry. 1999 Apr;156(4):544-549. DOI: 10.1176/ajp.156.4.544.

28. Cessak G, Rokita K, Dabrowska M, Sejbuk-Rozbicka K, Zaremba A, Mirowska-Guzel D, et al. Therapeutic equivalence of antipsychotics and antidepressants - a systemic review. Pharmacol Rep. 2016 Apr;68(2):217-223. DOI: 10.1016/j.pharep.2015.08.017.

29. Australian Government. Consultations on adoption of European Union guidelines in Australia: Outcome of previous consultation [Internet]. 2017 Jan 13 [cited 2019 Oct]. Available from: https://www.tga.gov.au/consultation/consultationsadoption-european-union-guidelines-australiaoutcome-previous-consultation

30. European Medicines Agency. Paliperidone palmitate depot suspension for injection $25 \mathrm{mg}, 50 \mathrm{mg}, 75 \mathrm{mg}$, $100 \mathrm{mg}$ and $150 \mathrm{mg}$ product-specific bioequivalence guidance [Internet]. 2016 Aug 1 [cited 2019 Jan]. Available from: https://www.ema.europa.eu/documents/scientificguideline/draft-paliperidone-palmitate-depotsuspension-injection-25-50-75-100-150-mg-productspecific_en.pdf

31. Committee for Medicinal Products for Human Use. Overview of comments received on paliperidone palmitate depot suspension for injection $25 \mathrm{mg}, 50$ $\mathrm{mg}, 75 \mathrm{mg}, 100 \mathrm{mg}$ and $150 \mathrm{mg}$ product-specific bioequivalence guidance (EMA/CHMP/474825/2016) [Internet]. $2017 \mathrm{Feb} 23$ [cited 2019 Jan]. Available from: https://www.ema.europa.eu/documents/comments/o verview-comments-received-paliperidone-palmitatedepot-suspension-injection-25-mg-50-mg-75-mg100/chmp/474825/2016 en.pdf

32. Health Canada. Policy issues from the Drugs Directorate - Submissions for generic parenteral drugs [Internet]. 1990 Mar 1 [cited 2019 Jan]. Available from: https://www.canada.ca/en/health- 
canada/services/drugs-health-products/drugproducts/applications-submissions/policies/policyissues-submissions-generic-parenteral-drugs.html

33. Health Canada. Regulatory Transparency and Openness Framework and Action Plan 2015-2018 [Internet]. 2015 Jun 23 [cited 2019 Oct]. Available from: https://www.canada.ca/en/healthcanada/corporate/transparency/regulatorytransparency-and-openness/regulatory-transparencyopenness-framework-action-plan-2015-2018.html

34. Fallu A, Dabourz F, Furtado M, Anand L, Katzman MA. A randomized, double-blind, cross-over, phase IV trial of oros-methylphenidate (CONCERTA $\left.{ }^{\circledR}\right)$ and generic novo-methylphenidate ER-C (NOVOgeneric). Ther Adv Psychopharmacol. 2016 Aug;6(4):237-251. DOI: $10.1177 / 2045125316643674$.

35. van Stralen JP. The clinical impact of switching attention deficit hyperactivity disorder patients from OROS $^{\circledR}$-MPH to Novo-MPH ER-C ${ }^{\circledR}$ : a paediatric practice review. Paediatr Child Health. 2013 Feb;18(2):70-73. DOI: 10.1093/pch/18.2.70.

36. U.S. Food and Drug Administration. Questions and answers regarding methylphenidate hydrochloride extended release tablets (generic Concerta) made by Mallinckrodt and UCB/Kremers Urban (formerly Kudco) [Internet]. 2016 Nov. 4 [cited 2019 May]. Available from: https://www.fda.gov/drugs/drugsafety-and-availability/questions-and-answersregarding-methylphenidate-hydrochloride-extendedrelease-tablets-generic

37. U.S. Food and Drug Administration. Update: Methylphenidate hydrochloride extended release tablets (generic Concerta) made by Mallinckrodt and Kudco [Internet]. 2016 Nov 7 [cited 2019 Apr]. Available from: https://www.fda.gov/Drugs/DrugSafety/ucm422568. htm

38. U.S. Food and Drug Administration. Draft guidance on methylphenidate hydrochloride [Internet]. [recommended 2012 Sep; revised 2014 Nov; 2018 Jul; cited 2018 Jul]. Available from: https://www.accessdata.fda.gov/drugsatfda_docs/psg Methylphenidate $\% 20$ Hydrochloride_draft_Oral $\% 20$ tab\%20ER_RLD\%2021121_RC07-18.pdf

39. Shram MJ, Quinn AM, Chen N, Faulknor J, Luong D, Sellers EM, et al. Differences in the in vitro and in vivo pharmacokinetic profiles of once-daily modified-release methylphenidate formulations in Canada: examination of current bioequivalence criteria. Clin Ther. 2012 May;34(5):1170-1181. DOI: 10.1016/j.clinthera.2012.02.010.

40. U.S. Food and Drug Administration. Product-specific guidances for generic drug development [Internet]. [cited 2018 Jul]. Available from: https://www.accessdata.fda.gov/scripts/cder/psg/ind

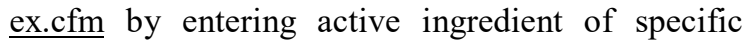
product in search bar.

41. Gupta D, Bhatia D, Dave V, Sutariya V, Varghese Gupta S. Salts of therapeutic agents: chemical, physiochemical, and biological considerations. Molecules. 2018 Jul;23(7). DOI: 10.3390/molecules23071719.

42. Jann MW, Ereshefsky L, Saklad SR. Clinical Pharmacokinetics of the Depot Antipsychotics. Clin Pharmacokinet 1985 Jul-Aug;10(4):315-333. DOI: 10.2165/00003088-198510040-00003.

43. Health Canada. Guidance document - Conduct and analysis of comparative bioavailability studies [Internet]. [effective 2018 Sep 1; cited 2018 Jul]. Available from: https://www.canada.ca/en/healthcanada/services/drugs-health-products/drugproducts/applications-submissions/guidancedocuments/bioavailability-bioequivalence/conductanalysis-comparative.html

44. Endrenyi L, Tothfalusi L. Metrics for the evaluation of bioequivalence of modified-release formulations. AAPS J. 2012 Dec;14(4):813-819. DOI: 10.1208/s12248-012-9396-8.

45. Bois FY, Tozer TN, Hauck WW, Chen ML, Patnaik R, Williams RL. Bioequivalence: performance of several measures of rate of absorption. Pharm Res. $1994 \mathrm{Jul} ; 11(7): 966-974$.

46. U.S. Government. Docket ID: FDA-2013-P-0608 Janssen Research and Development, L.L.C. (Ropes \& Gray, LLP) citizen petition [Internet]. 2013 May 10 [cited 2018 Jul]. Available from: https://www.regulations.gov/document?D=FDA2013-P-0608-0001 by selecting PDF link.

47. U.S. Food and Drug Administration. Guidance for industry - Bioequivalence studies with pharmacokinetic endpoints for drugs submitted under an ANDA Draft Guidance [Internet]. 2013 Dec [cited 2019 Jul]. Available from: https://www.fda.gov/regulatory-information/searchfda-guidance-documents/bioequivalence-studiespharmacokinetic-endpoints-drugs-submitted-underabbreviated-new-drug

48. European Medicines Agency. Guideline on the pharmacokinetic and clinical evaluation of modified release dosage forms (EMA/CPMP/EWP/280/96 Corr 1) [Internet]. [effective 2015 Jun 1; cited 2019 Jul]. Available from: https://www.ema.europa.eu/en/pharmacokineticclinical-evaluation-modified-release-dosage-forms 


\section{SUPPLEMENTARY MATERIAL}

\section{Comparative Summary of Bioequivalence Requirements for Paliperidone Palmitate LAI in Australia, Europe, United States, and Canada}

No international consensus exists on bioequivalence requirements for paliperidone palmitate LAI. The EMA and U.S. FDA have each issued their own product-specific guidelines for new formulations of a paliperidone palmitate LAI product referencing INVEGA SUSTENNA ${ }^{\circledR}$, Australia has adopted the EMA guidelines, and Health Canada has not published guidelines for generic parenteral drugs that are modified release preparations, guidelines are summarized in Table $1(17,18,29,32)$. Note that the EMA and U.S. FDA guidelines have important differences in several specific requirements. A list of the cited pharmacokinetic parameters and related definitions is provided in Table 2.

Table 1. Comparative Summary of Bioequivalence Guidelines for Paliperidone Palmitate LAI ${ }^{1}$

\begin{tabular}{llll}
\hline & EMA & U.S. FDA & Canada \\
\hline $\begin{array}{l}\text { Bioequivalence } \\
\text { study design }\end{array}$ & Cross-over or parallel design ${ }^{2}$ & Cross-over or parallel design & Category IV products - \\
Need to request information.
\end{tabular}

Single dose: in healthy volunteers (if feasible) or patients stabilized on other antipsychotic medication.

Multiple dose: in patients.

Subjects
In healthy volunteers (if feasible) or in patients stabilized on other antipsychotic medication.

\section{Single dose: N/A}

Multiple dose: steady state

Male and nonpregnant female patients with schizophrenia or schizoaffective disorder who are already receiving a stable regimen of paliperidone palmitate extended release suspension via the intramuscular route. Patients who are already receiving any dosage regimen of paliperidone palmitate injection every month would be eligible to participate in the study by continuing their established maintenance dose.

(1) FDA does not recommend that studies be conducted using healthy subjects or patients on a different antipsychotic treatment.

(2) Both sites of injection (gluteal and deltoid) should be included in the study design for adequate site representation to support the results of the study.

(3) More than three doses may be required to reach steady state. PK

\footnotetext{
${ }^{1}$ Australia has adopted the EMA guidance: Paliperidone palmitate depot suspension for injection $25 \mathrm{mg}, 50 \mathrm{mg}$, $75 \mathrm{mg}, 100 \mathrm{mg}$ and $150 \mathrm{mg}$ productspecific bioequivalence guidance.

${ }^{2}$ As intra-subject variability of the reference product was not reviewed to elaborate this product-specific bioequivalence guideline, it is not possible to recommend at this stage the use of a replicate design to demonstrate high intra-subject variability and widen the acceptance range of $\mathrm{Cmax}$, $\mathrm{C} \tau$,ss and partial AUC. If high intra-individual variability (CVintra $>30 \%$ ) is expected, the applicants might follow respective guideline recommendations.
} 
data should be submitted to demonstrate that steady state has been reached for each individual. (4) All strengths of the test product need to be from the same bulk in order for all strengths of the Test to be administered in the $\mathrm{PK} \mathrm{BE}$ study.

Strengths Any dose/strength (if the test product has the same concentration of active substance as the reference for all the strengths)

Waivers

Analyte ${ }^{3}$

\section{Bioequivalence assessment \\ Main pharmacokinetic variables: Single dose: $\mathrm{AUC}_{0-\mathrm{t}}, \mathrm{AUC}_{\mathrm{inf}}, \mathrm{C}_{\max }$ and $\mathrm{T}_{\max }$}

Metabolite (paliperidone) measured from plasma/serum (Bioequivalence should be based on paliperidone)

If a single-dose study with the highest strength has shown that there is low

risk of accumulation (i.e. $\mathrm{AUC}_{\tau}>90 \%$ of $\mathrm{AUC}_{\mathrm{inf}}$ ), the multiple-dose study may be waived. If low degree of accumulation is expected, the applicants might follow respective guideline recommendations.

Multiple dose: $\mathrm{AUC}_{0-\tau}, \mathrm{C}_{\max , \mathrm{ss}}, \mathrm{C}_{\tau, \mathrm{ss}}$
$39 \mathrm{mg} / 0.25 \mathrm{~mL}, 78 \mathrm{mg} / 0.5 \mathrm{~mL}, 117$ $\mathrm{mg} / 0.75 \mathrm{~mL}, 156 \mathrm{mg} / \mathrm{mL}, 234$ $\mathrm{mg} / 1.5 \mathrm{~mL}$

Waiver request of in vivo testing: $39 \mathrm{mg} / 0.25 \mathrm{~mL}, 78 \mathrm{mg} / 0.5 \mathrm{~mL}, 117$

$\mathrm{mg} / 0.75 \mathrm{~mL}$, and $234 \mathrm{mg} / 1.5 \mathrm{~mL}$ (if not studied in vivo) based on (i) acceptable bioequivalence study on the $156 \mathrm{mg} / \mathrm{mL}$ strength, (ii) acceptable in vitro dissolution testing of all strengths, and (iii) proportional similarity of the formulations across all strengths.

Paliperidone in plasma

In the evaluation of bioequivalence of the multiple dose study, the following pharmacokinetic data should be submitted for paliperidone: - Individual and mean blood drug concentration levels in a dosing interval after steady state is reached - Individual and mean trough levels ( $\left.\mathrm{C}_{\min } \mathrm{ss}\right)$

- Individual and mean peak levels ( $\left.\mathrm{C}_{\max } \mathrm{ss}\right)$

- Calculation of individual and mean steady-state $\mathrm{AUC}_{\tau}\left(\mathrm{AUC}_{\tau}\right.$ is AUC during a dosing interval at steady-state)

- Individual and mean percent fluctuation $\left[=100 *\left(\mathrm{C}_{\max } \mathrm{ss}-\mathrm{C}_{\min } \mathrm{ss}\right) / \mathrm{C}_{\text {average }}\right.$ SS]

- Individual and mean time to peak concentration

\footnotetext{
${ }^{3}$ The prodrug, paliperidone palmitate, is not reliably measurable in plasma.
} 


\section{EMA}

90\% Confidence $\mathbf{9 0 \%}$ confidence interval: 80.00 Interval
$125.00 \%$ for $\mathrm{AUC}_{0-\mathrm{t}}, \mathrm{AUC}_{\mathrm{inf}}, \mathrm{C}_{\max }$, $\mathrm{AUC}_{0-\tau}, \mathrm{C}_{\max , \mathrm{ss}}$ and $\mathrm{C}_{\tau, \mathrm{ss}}$. Comparable median and range for $\mathrm{T}_{\max }$.
U.S. FDA

The $90 \%$ confidence interval for the ratio of the geometric means of the pharmacokinetic parameters (AUC and $\mathrm{C}_{\max }$ ) should be within $80-125 \%$. Fluctuation for the test product should be evaluated for comparability with the fluctuation of the reference product. The trough concentration data should also be analyzed to verify that steady-state was achieved prior to pharmacokinetic sampling.

Table 2. Definitions of the Pharmacokinetic Parameters Cited in EMA and U.S. FDA Product-Specific Bioequivalence Requirements for Paliperidone Palmitate LAI

\begin{tabular}{ll}
\hline U.S. FDA (17, 47) & Definition \\
\hline Pharmacokinetic Parameter & Minimum or trough concentrations at steady-state \\
\hline $\mathrm{C}_{\min } \mathrm{SS}$ & $\begin{array}{l}\text { Peak concentrations during the dosing interval at } \\
\text { steady-state }\end{array}$ \\
$\mathrm{C}_{\max } \mathrm{SS}$ & AUC during a dosing interval at steady-state \\
& Average plasma concentration at steady-state \\
$\mathrm{AUC}_{\tau}$ & \\
$\mathrm{C}_{\text {average }} \mathrm{SS}$ & Definition \\
\hline EMA (18, 48) & Area under the plasma concentration curve from \\
\hline Pharmacokinetic Parameter & administration to last observed concentration at time t \\
\hline $\mathrm{AUC}_{0-\mathrm{t}}$ & Area under the plasma concentration curve \\
$\mathrm{AUC}_{\mathrm{inf}}$ & extrapolated to infinite time \\
$\mathrm{C}_{\max }$ & Maximum plasma concentration \\
$\mathrm{T}_{\max }$ & Time until $\mathrm{C}_{\text {max }}$ is reached \\
$\mathrm{AUC} \mathrm{C}_{0-\tau}$ & AUC during a dosage interval \\
$\mathrm{C}_{\max , \mathrm{ss}}$ & Maximum plasma concentration at steady state \\
$\mathrm{C}_{\tau, \mathrm{ss}}$ & Concentration at the end of the dosing interval at \\
& steady state \\
\hline
\end{tabular}

